\title{
Referrals to neurologists for headaches not due to structural disease
}

\author{
RAY FITZPATRICK, ANTHONY HOPKINS \\ From the Social Research Unit, Bedford College, London and the Department of Neurological Sciences, \\ St Bartholomew's Hospital, London
}

SUMmaRY Patients attending neurological clinics with headaches that proved not to be due to clearly defined structural disease were interviewed before and after the consultation and approximately one year later. Their expectations of the consultation were ill-formed. About two-thirds of the patients had fears about organic disease although few had psychiatric morbidity. These fears were generally dispelled by the consultation. About one-third of the patients were dissatisfied by the consultation, nearly all by what the neurologist said rather than by what technical procedures he did or did not undertake. Women with a long history of migraine, with significant psychiatric morbidity, and who had initiated the referral themselves were particularly likely to be dissatisfied. Although most patients were still having headaches one year later, visits to the general practitioner for this symptom had greatly declined.

Headache is one of the commonest ailments suffered by Man in the developed countries. Most episodes, of course, are either ignored or self treated with simple analgesics. Wadsworth ${ }^{1}$ and Banks et $a l^{2}$ found, in their surveys of symptoms in the community, that headache was the symptom most often dealt with by lay medication. However, some find their headaches so frequent, or so severe, at least by their own terms of reference, that they seek medical advice. From the second national study on morbidity in general practice, ${ }^{3}$ it can be calculated that the patient consulting rate for all types of headache was 16 per thousand per year. ${ }^{4}$ As a comparison, the patient consulting rate for epilepsy, another common neurological disturbance, was only 2.9 per thousand per year.

Some patients consulting their general practitioners are referred to a neurologist or to a hospital physician for specialist consultation and advice, although clinical experience informs the profession that the chances of finding a clearly defined "explanation" for the headaches are slim. Since the Second World War, neurological services have become developed in Europe and in the United

Address for reprint requests: Dr Anthony Hopkins, Department of Neurological Sciences, St Bartholomew's Hospital, London EC1A 7BE, UK.

Received 1 April 1981 and in revised form 10 August 1981 Accepted 1 September 1981
States. Neurologists are available in larger numbers, and so, in common with general practitioners, spend a greater proportion of their time advising about symptoms that often do not appear to have a basis in clearly defined abnormal physiology or pathology. It has been calculated that in the United Kingdom there are twenty times more referrals to hospitals for headache and migraine than for multiple sclerosis. ${ }^{4}$

Appreciation of these figures, of the apparently increasing expectations of satisfaction of symptoms not due to definable organic disease, and doubts about the worth of neurological consultation in these circumstances have led us to evaluate the role of referral to neurologists in the management of headaches. This paper reports the characteristics of patients referred for headaches, the typical forms of management, and the outcomes of such referral.

\section{Methods}

The 42 neurologists holding consultant contracts in neurology in the North East and North West Thames Health Regions were approached by one of us and the aims of the project explained. Twenty-four neurologists agreed to co-operate, 18 of whom actually provided us with patients for the study sample from their outpatient clinics.

Our criteria for inclusion in the study were any patient who (a) was a new referral for headache as a predominant symptom rather than a "follow-up", (b) was aged 16 yl 
or over, (c) was not suspected, after investigation, of having a serious space occupying lesion. Liaison with the clerical staff of 11 hospitals informed us of the appointment time and date of 111 patients who met our first two criteria; two were excluded because the neurologist suspected an expanding lesion, although we subsequently learned that in neither case did investigations reveal the suspected lesion. Thus 109 patients were interviewed briefly at the hospital before seeing the neurologist. We successfully contacted 102 patients at home approximately three weeks later, of whom seven refused to participate in a second interview. Thus second (main) interviews were completed with $95(87 \%)$ of the original 109 patients. The patients whom we were unable to interview on the second occasion did not differ from the main sample in any item of information that we could obtain about them. Sixty-eight per cent of the sample were obtained from referrals to London Teaching Hospitals and $32 \%$ from London and provincial general hospitals. In the first interview we obtained information from the patients about symptoms, worries about symptoms and their expectations of the neurologist. In the second interview we obtained a fuller account of their history of headaches, prior experience of medical and non-medical treatment, circumstances of referral, and satisfaction with their hospital visit. We used a nonschedule standardised interview which was tape-recorded and analysed with rating scales developed from a pilot study. In the second interview we also obtained a standardised account of the patient's recent psychiatric state by means of the Present State Examination (PSE), an instrument developed by Wing et $a l^{5}$ which has high reliability in eliciting and recording psychiatric symptoms. The significance of all relationships between variables reported in the results was measured by means of the chi-square test.

\section{Results}

DEMOGRAPHIC AND SOCIAL CHARACTERISTICS OF THE SAMPLE

Figure 1 shows the age and sex distribution of the sample compared with that of England and Wales.

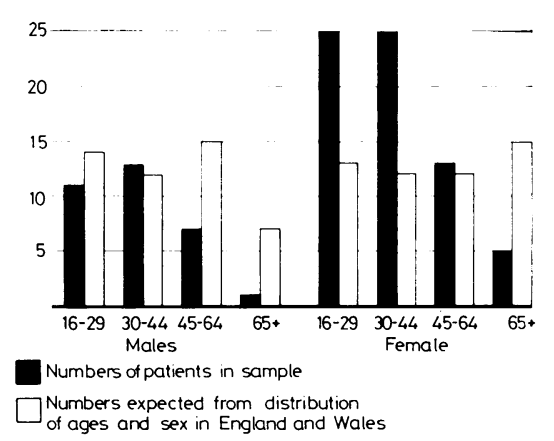

Fig 1 Distribution of age and sex of patients referred for headaches.
As with other studies of headache sufferers, the majority $(69 \%)$ were female, most of them in the younger age groups.

The social class background of the sample (using the Hope-Goldthorpe Scale ${ }^{6}$ is shown in fig 2. There is an excess of patients from social groupings 2 and 3. This excess of middle-class patients is even more salient if we consider only those in the sample who were diagnosed as migraine, $47 \%(27 / 58)$ of whom were of social group 2 and 3, more than twice as many as expected from the social class distribution of the country as a whole.

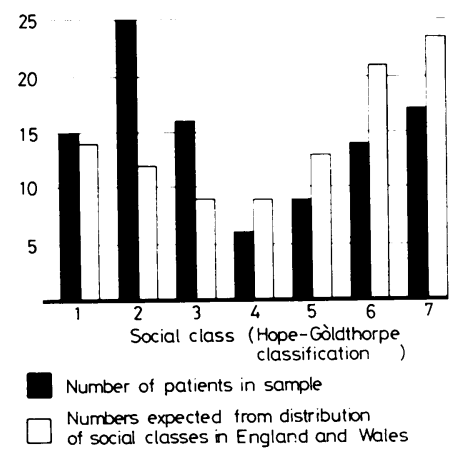

Fig 2 Distribution of social class of patients referred for headaches. ${ }^{6}$

\section{CLINICAL CHARACTERISTICS}

Figure 3 shows the diagnosis made by the neurologists, and the presence or absence of three factors - unilaterality of headaches, sickness and aura. Although the neurologists made the diagnosis of migraine in 58 patients, fig 3 indicates that this may have been ill-founded in some cases. Only 21 patients suffered classical migraine as defined by the Ad Hoc Committee on Classification of Headaches. ${ }^{7}$

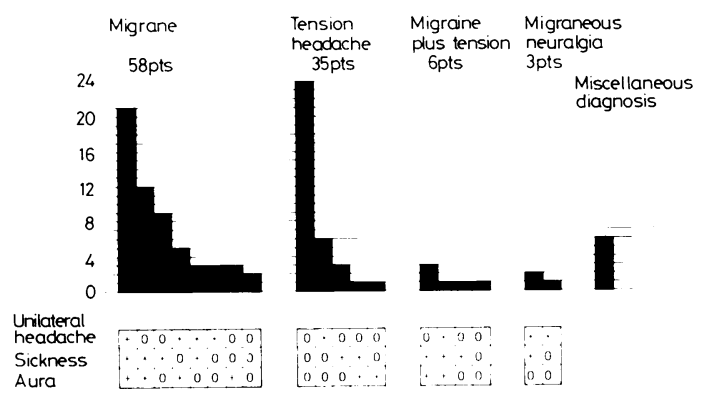

Fig 3 Diagnosis made by hospital doctors in neurological clinics in relation to the presence or absence of certain symptoms-unilaterality of headache, nausea or vomiting, a specific neurological aura. 
Figure 4 shows the reported frequency and typical duration of headaches suffered by the sample, compared with those found by Waters ${ }^{8}$ in his survey of headache in the community. Those patients referred have headaches that were both more frequent and longer lasting. Forty per cent of our sample were suffering from headaches twice weekly or more frequently compared to only $5 \%$ in the community survey. Thirteen of the 109 patients in the sample reported headaches that were constantly present. Thirty per cent had suffered headaches for more than ten years before referral, $38 \%$ for between one and ten years, and $32 \%$ for less than one year.

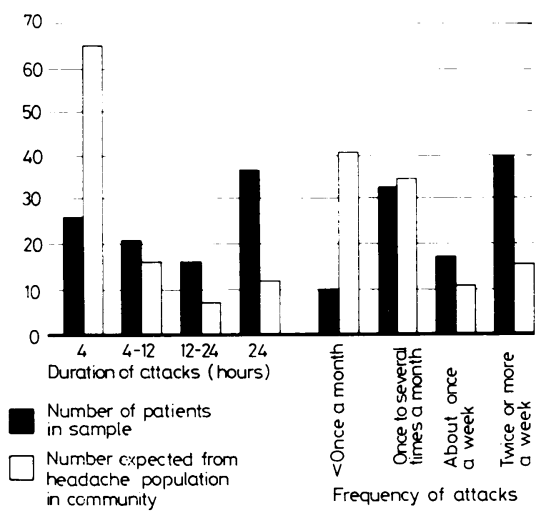

Fig 4 Duration and frequency of headaches amongst patients referred to hospital compared with headaches in the community. ${ }^{8}$

PSYCHIATRIC MORBIDITY

We made judgements, on the basis of the interviews, of the degree of psychiatric morbidity suffered by the sample. The results of these ratings are shown in table 1. All disorders were affective. The division into depression or anxiety was made on the basis of the grouping of scores of the PSE. An alternative classification of the sample was made solely on the basis of the PSE scores. Wing et al ${ }^{9}$ indicates that a score of 11 or more is found in $92 \%$ of psychiatric outpatient and inpatient samples, but in only $13 \%$ in a general population. It can thus be used as a cut-off score for an operational definition of psychiatric "caseness" in the sense used by Brown and Harris, 10 "a psychiatrist would not be surprised to see her in an outpatient clinic". The interviewers ratings of psychiatric morbidity and the PSE score were highly correlated -80 of the 95 patients were placed in the same position by both methods of classification. Only one patient was rated as showing severe psychiatric morbidity by the interviewer but scored in the low/normal group in the PSE.
Table 1 Psychiatric morbidity in sample of referred patients with headache

\begin{tabular}{lll}
\hline A. Interviewer's rating & & \\
Normal & 60 & Moderate to Severe \\
& Mild & 5 \\
Depression & 14 & 1 \\
Anxiety & 4 & 4 \\
Depression and Anxiety & 7 & \\
B. Present State Examination Scores & \\
Scores & 61 & \\
$0-5$ & 19 & \\
$6-10$ & 15 & \\
$>11$ & & \\
\hline
\end{tabular}

For the purposes of analysis we grouped together the 18 patients who were rated as extensively psychiatrically impaired by either method. Twelve of the 18 patients were currently receiving a prescription for at least one psychotropic drug prescribed by their general practitioner and one patient was taking a psychotropic drug prescribed by a psychiatrist. However, in only six of these 18 patients was any mention made in the referral letter to the patient's psychiatric state or of the current psychotropic drug treatment.

There were no differences in psychiatric morbidity between men and women, and no age group in this sample was particularly likely to have psychiatric symptoms. However, we did find that working class patients (Hope-Goldthorpe classes 6,7) were more likely than middle class patients to have psychiatric symptoms $(p<0.02)$ and were strongly represented in the group of 18 "cases" of psychiatric impairment $(p<0.01)$. Seven out of the 13 patients who had continuous headaches were in this group of 18 "cases". Those patients whom the neurologist diagnosed as having tension headache or tension headache and migraine combined were rather more likely to have psychiatric symptoms but the difference was not significant.

\section{ANXIETIES ABOUT ORGANIC DISEASE}

Neurologists are aware that many patients presenting in their clinics with headache are afraid that they may have some serious intracranial disease such as a brain tumour or an impending cerebral haemorrhage. Eighteen patients told us of people known to them who had experienced headaches which were subsequently associated with such conditions. We rated the presence of such fears from our interviews with patients prior to their seeing the neurologist. We were concerned to assess fears about serious illness, rather than situational anxiety produced by the hospital visit. We took the following factors into account to rate fear of diseasespontaneous mention of organic disease, indication of "recognition" or "relief" from our questioning 
about it, emotional tone of voice in discussing ideas about serious illness, evidence that worry about serious illness was disruptive to the person's life and involved thoughts that could not easily be controlled or dismissed, evidence of other people being aware of the concern, evidence of focus on particular diseases and/or known cases of serious disease.

We rated $65(60 \%)$ of the sample, with high inter-rater reliability, as having fears about serious illness and $44(40 \%)$ as having insignificant or no fears.

Certain factors were correlated with worry about organic illness. Patients having headaches more often than twice a week were more worried $(p<0.01)$ than those whose headaches were less frequent; women were more likely to be worried than men $(\mathrm{p}<0.05)$; those subsequently diagnosed as having tension headaches were rather more likely to be worried than those with migraine as a diagnosis $(p<0 \cdot 1)$; those with headaches for less than two years were rather more likely to be worried than those with headaches for longer periods $(p<0 \cdot 2)$.

We also considered the relationship between psychiatric morbidity and fear about serious illness. Those rated as anxious or depressed were more likely to be afraid of serious illness $(p<0.05)$. However, there was no relationship between the extent of psychiatric symptoms and the likelihood of being afraid of serious illness. All five patients rated as being anxious were worried about organic disease, and 12 out of 19 of those rated as being depressed. However, the majority $(57 \%)$ of those whom we rated as afraid of serious illness did not have psychiatric symptoms. Clearly such concerns do not necessarily arise from psychiatric morbidity.

General practitioners did not recognise worries about organic disease, or, if they did, they did not think this worth spelling out in the referral letter. Of the 65 patients that we rated as being worried about organic illness, mention was made of patients' fears or an explicit request made for help in reassuring the patient in only 11 of the letters.

\section{MANAGEMENT AT HOSPITAL}

Sixty-three of the sample of 109 were seen by a consultant, and 46 by a junior doctor. In 47 cases the hospital doctor undertook investigations, which are shown in table 2 . Six of the 47 were investigated for problems unrelated to the presenting headache. The majority (62) were not investigated in any way. Patients were somewhat less likely to undergo investigations if they were seen by a consultant $(38 \%)$ than if they were seen by a junior doctor $(48 \%)$. Similarly, if we only consider the cases that were investigated, consultants usually chose a skull radiograph as a sole investigation $-57 \%$ of their
Table 2 Number of investigations initiated by the neurologist (some patients received more than one test)

(For headache unless otherwise stated)

Skull radiograph

EEG

Blood count

ECG and radiograph for hypertension

Referral to eye department for unusual eye-signs

Liver function test

Thyroid function test

investigations-whereas only $24 \%$ of junior doctors' investigations comprised a skull radiograph alone. They more often arranged more complex or multiple investigations.

At least 27 different proprietary drugs were prescribed by the hospital doctors for the sample. The types of drugs are shown in table 3 . Forty per cent $(14 / 35)$ of those diagnosed as tension headache and $16 \%(9 / 58)$ of those diagnosed as migraine were not prescribed any medication. Forty-eight of 109 patients were seen at one or more follow-up consultations.

Table 3 Types of medication prescribed by hospital doctors for 93 patients with migraine or tension headache

\begin{tabular}{lll}
\hline & $\begin{array}{l}\text { Migraine } \\
\text { (58 patients) }\end{array}$ & $\begin{array}{l}\text { Tension headache } \\
\text { (35 patients) }\end{array}$ \\
\hline $\begin{array}{l}\text { Prophylactic medication } \\
\quad \text { pizotifen, clonidine, }\end{array}$ & \\
$\quad$ propranolol) & 24 & 0 \\
Ergotamine tartrate & 16 & 0 \\
Anti-emetic & 14 & 0 \\
Analgesics & 13 & 2 \\
Benzodiazepines & 2 & 8 \\
Antidepressants & 5 & 9 \\
No medication prescribed & $9(16 \%)$ & $14(40 \%)$ \\
(27 different drugs prescribed) & & \\
\hline
\end{tabular}

\section{PATIENT SATISFACTION}

We rated how satisfied patients were with their visit to the neurological clinic on the basis of their views expressed in the main home interview. Twenty-five per cent $(24 / 95)$ of patients were rated as dissatisfied with the medical aspects of their visit to the hospital. The most commonly cited grounds for dissatisfaction $(12 / 24)$ was that the doctor had been too superficial or routine in questioning them about aspects of their histories that they considered relevant. Six out of the 24 focused their critical comments on receiving physical examinations that they considered too cursory, and seven patients expressed dissatisfaction mainly in terms of inadequate investigations (one patient expressed equal dissatisfaction on two grounds). 
Demographic and social variables such as age, sex, social class, education and marital status were not significantly related to satisfaction, nor were the following variables related to patient managementwhether or not the patient was investigated, whether or not a follow-up visit was arranged, whether or not the patient was seen by a consultant rather than by a doctor in training, whether or not the referral was to a teaching hospital.

There were, however, certain features clearly associated with patient dissatisfaction. Those with a history of headaches for more than one year were much more likely to be dissatisfied than those with shorter histories $(p<0.01)$. Patients with migraine were more likely to be dissatisfied than those with tension headaches $(p<0.02)$. Patients with significant psychiatric symptoms were also more dissatisfied $(\mathrm{p}<0.02)$.

At the first interview before the patients had seen the neurologist, we attempted to ascertain the patients' views of their problems. Twenty-three patients clearly defined their problem in terms of migraine. The remainder of the sample varied in their degree of uncertainty and lack of clarity regarding their illness. The former group-those clearly defining their problem as migraine-were much more likely $(\mathrm{p}<0.001)$ to be the respondents whom we were later to rate as dissatisfied with the contribution made by the hospital doctors. It is also interesting that these were often the patients who had made a specific request for specialist referral $(\mathrm{p}<0.05)$.

We separately rated patients' satisfaction with information received during their hospital visitsfor example about the implications of the diagnosis and the future. Twenty-seven per cent were dissatisfied about this aspect of their care. The most commonly expressed criticisms by this group were that they were not told what their diagnosis meant, and that there was no discussion of the causes of their disorder or of actions that the patient might take to avoid or alleviate episodes of headache.

Thirty-four patients were rated as dissatisfied on one or other of the two aspects of their visit, but only 16 were dissatisfied on both aspects so we do not feel we are reporting a response set. Moreover, those who expressed critical comments regarding the hospital visit were not found to have been any more critical than others about their general practitioner.

\section{REASSUR ANCE}

Of the 65 patients who expressed fears about serious illness, $39(60 \%)$ were rated as completely reassured after the consultation. Eighteen $(28 \%)$ were partly reassured but expressed some remaining concerns.
Eight $(12 \%)$ of the sample were rated as wholly unreassured about concerns of serious illness. None of our measures of patient characteristics or of form of medical management seemed to be associated with failure of reassurance. However, those patients who were rated as critical of information received at the hospital were much more likely $(p<0.01)$ to have felt less than completely reassured.

\section{LONG-TERM OUTCOME}

We attempted to assess the long-term outcome for this sample of referrals. We succeeded in re-interviewing 74 of the sample one year after their hospital visit. A fuller analysis of this follow-up will be reported elsewhere but one indication of outcome, which supports the results of a study by Grove et $a l^{11}$ on referrals for tension headache, is that there was a considerable reduction in numbers of consultations with the general practitioner for headache in the year after referral (fig 5). Forty-

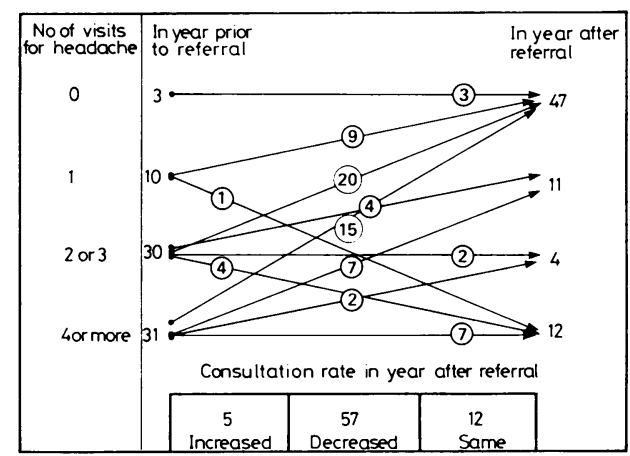

Fig 5 Effect of neurological consultation on general practitioner consultations for headache.

seven out of the 74 patients did not consult their general practitioner for headache in the year after referral and a further 14 patients visited the doctor less often than they had prior to referral. However, only 17 patients reported that their headaches had disappeared in the year after the hospital visit. Thus a substantial number of patients reduced the number of visits to their doctor despite continuing to experience headaches. The possibility exists that this was due to despair with orthodox medicine and that patients resorted to faith healing, osteopathy, hypnotism or herbalism. However, only seven patients reported seeking such help, suggesting that disillusionment with orthodox medicine was not a common response. 


\section{Discussion}

With increasing national wealth, many people expect to be free from all symptoms even if such symptoms do not have any clearly defined basis in structural disease. Consultants in all specialities see such patients-the gastroenterologists see patients with the irritable bowel syndrome and chronic constipation, the cardiologists see those with nondescript chest pain, and the psychiatrists see those who are simply unhappy. The neurologist's equivalent is those with headaches, and this paper focuses on one particular aspect of management of such patients-a specialist consultation and its outcome. As the management of symptoms, rather than the management of diseases, is proving to be an increasing part of a consultant's work, it is important to analyse the way in which this work is done, and its success.

A distinction has often been made in medical sociology between "disease" which is a description of a pathological diagnosis within the framework of present medical knowledge and "illness" which is the layman's perspective on his problem. This distinction draws our attention to areas of potential contrast or indeed conflict between patients and doctors. It might be predicted that the management by the neurologist of headache not due to structural disease would be an instance of such conflict and it was from this perspective that we set out in this study to explore the needs and expectations that patients themselves expressed. At the preliminary interview we attempted to assess the expectations of the patients of the neurologist. However, with few exceptions we found the patients unfamiliar and uncomfortable with the task of expressing their needs at the time they come to hospital, insisting, for example, that it was "a matter for the doctor to decide". In any case, few had any substantial notion of the role of the neurologist, and indeed only $46 \%$ knew the kind of specialist that they were about to see. Only after the experience did ideas emerge and clarify - a phenomenon also reported of the illness behaviour of general practice patients. ${ }^{12}$ Neither those whom we rated as initially clear about the nature of their headaches, nor the group who had themselves requested their referral had any more precise or explicitly formulated expectations than others. Nevertheless, it was possible to delineate more indirectly a number of analytically separate needs that the neurological referral could be said to be fulfilling with varying degrees of success.

First, nearly two-thirds of the sample were found to have significant fears about serious illnessa problem of which neurologists are well aware. This level of "nosophobia" is high but is of the same order as reported by Mayou ${ }^{13}$ in outpatients clinics in cardiology and venereology. We noted a statistical association with our ratings of anxiety and depression, but found that many patients apparently psychologically "normal" also had such fears. The PSE is based on hospital psychiatric "caseness". As Williams et al ${ }^{14}$ have pointed out, methods of conceptualising and measuring forms of morbidity more relevant to the distressed person in the community must be developed.

The majority of patients were reassured, and such reassurance was gained through the experience of seeing the specialist per se, rather than through any particular procedure he carried out. This, and the "vanishingly small chance that a person with headache and normal findings on neurological examination will have anything discovered by CT brain scan, or skull roentgenogram" 15 should be sufficient to allow neurologists to continue to rely upon a careful history and physical examination. Our finding that patients who were rated as unreassured also felt that they had not learned enough from the consultation about the headaches should also encourage neurologists to spend more time on explanation and less on arranging investigations. ${ }^{16}$

The communication of diagnosis and of the implications for the individual was clearly a second important function of the hospital visit and one in regard to which a substantial number of patients were critical. Such criticism is not surprising when neurologists' own conceptual model of tension headache and migraine is largely speculative. Figure 3 indicates the idiosyncratic use of variables usually considered to be important in the diagnosis of migraine. Factor analysis of clinical variables in patients prone to headaches has also failed to reveal clearly defined syndromes. ${ }^{17}$ Given the imprecise state of medical knowledge in this field, doctors could well explicitly admit to their patients that only a limited amount of personalised advice can usefully be offered. Greater use could perhaps be made of instructional pamphlets. ${ }^{18}$

This comment is particularly relevant to that group of patients whom we found most critical of their hospital visit whom, without any implication of disparagement, we may follow McIntyre ${ }^{19}$ in calling "expert" migraine sufferers. Apparent in many of their reflections on the hospital visit was an underlying theme based on their long-term experiencethat migraine constitutes a complex combination of organic and psycho-social factors that require to be treated properly by an investigation in depth of an individual's unique medical and social biography. This perspective clearly clashes with that of the doctor, who, in terms of a standard agenda of diagnosis and treatment of migraine, may gain little 
from such an exhaustive approach to individual history. In this sense, there is an immense potential for conflict between the perspective of "illness" held by such patients, and the doctors concerned with "disease". Inspection of our data and of the variables related to dissatisfaction with the consultation can be used to construct a paradigm of the dissatisfied patient - an anxious or depressed migraine sufferer with a history longer than one year, who knows a fair amount about the illness and who herself has initiated referral. From personal experience, it is just this group of patients who seek referral to special Migraine Clinics. Henryk-Gutt and Linford Rees $^{20}$ have already demonstrated differences in scores on scales, designed to assess personality and "hostility" between those attending a Migraine Clinic, and migraine sufferers in general. In order to justify the establishment of such clinics, the outcome of referrals to them should be studied.

One "latent" function of specialist referral which we intend to explore further is the reduction of the subsequent "burden" on the general practitioner that is clearly indicated by these results and those of Grove et al. ${ }^{11}$

Finally, we draw attention to the social distribution of usage of neurological referral. We found that amongst migraine sufferers middle class patients were over-represented; this has also been reported by Waters for attendances in general practice. ${ }^{21}$ Conversely, although under-represented in our sample, working class patients were more likely to present with headache as part of a wider clinical history of psychiatric symptoms, in the management of which the neurologist would seem to have a minimal role. Usage of medical services is often discussed in terms of under and over utilisation. Our results indicate that research should also include appropriate utilisation. Research of this nature indicates above all that discussion of rational and effective use of specialist resources will have to come to terms with fundamental issues of "need", "want", and "demand". ${ }^{22}$ The first step of such a discussion must be a recognition of the complexity and multiplicity of needs and their origins.

We thank Olivia Harvard Watts for conducting many of the interviews, Professor George Brown for advice and encouragement, Dr Elaine Murphy for training in the use of the PSE, and the patients and doctors for allowing us to interview them.

This work was supported by a grant from the Department of Health and Social Security.

\section{References}

${ }^{1}$ Wadsworth ME, Butterfield WJ, Blaney R. Health and sickness, the choice of treatment. London: Tavistock, 1971.

2 Banks MH, Beresford SA, Morrell DC, Waller JJ, Watkins CJ. Factors influencing the demand for primary medical care in women aged $20-44$ years: a preliminary report. Int J Epidemiol 1976;4:189-95.

${ }^{3}$ Office of Population Censuses and Surveys. Morbidity statistics from general practice 1971-2. London: HMSO, 1974.

4 Hopkins AP. Consultants' work load. Lancet 1976; i:956-8.

${ }^{5}$ Wing JK, Cooper JE, Sartorius N. Description and classification of psychiatric symptoms. London: Cambridge University Press, 1974.

${ }^{6}$ Goldthorpe JH, Hope K. The social grading of occupations: a new approach and scale. Oxford: Clarendon Press, 1974.

7 Ad Hoc Committee on Classification of Headache. Classification of headache. JAMA 1962;179:717-8.

${ }^{8}$ Waters WE. The Pontypridd headache survey. Headache 1974;14:81-90.

${ }^{9}$ Wing JK, Mann SA, Leff JP, Nixon JM. The concept of a 'case' in psychiatric population surveys. Psycholog Med 1978;8:203-17.

${ }^{10}$ Brown GW, Harris T. Social origins of depression. A study of psychiatric disorders in women. London: Tavistock, 1976.

${ }^{11}$ Grove JL, Butler P, Millac PAH. The effect of a visit to a neurological clinic upon patients with tension headache. Practitioner 1980;224:195-6.

${ }^{12}$ Stimson G, Webb B. Going to see the doctor. London: Routledge and Kegan Paul, 1975.

${ }^{13}$ Mayou R. The nature of bodily symptoms. Brit $J$ Psychiat 1976;129:55-60.

${ }^{14}$ Williams P, Tarnopolsky A, Clare AW. Recent advances in the epidemiological study of minor psychiatric disorder. $J$ R Soc Med 1980;73:679-80.

${ }^{15}$ Larson EB, Omenn GS, Lewis H. Diagnostic evaluation of headache. $J A M A$ 1980;243:359-62.

${ }^{16}$ Editorial. Lancet 1980;ii :898-9.

${ }^{17}$ Ziegler DK, Hassanein R, Hassanein K. Headache syndromes suggested by factor analysis of symptom variables in a headache-prone population. J Chron Dis 1972;25:353-63.

${ }^{18}$ Editorial. Pamphlets for patients. Postgrad Med 1974; 56:220.

19 McIntyre S, Oldman D. Coping with migraine. In: Davis A, Horobin G, eds. Medical Encounters. London: Croom Helm, 1977.

${ }^{20}$ Henryk-Gutt R, Linford-Rees W. Psychological aspects of migraine. J Psychosomat Res 1973;17:141-53.

${ }^{21}$ Waters WE. Epidemiology of migraine. In: Pearce J, ed. Modern topics in Migraine. London: Heinemann, 1975.

22 Jeffers JR, Bognanno MF, Bartlett JC. On the demand versus the need for medical services and the concept of 'shortage'. Amer J Publ Health 1971 ;61 :46-63. 